\title{
Variation in mistletoe seed deposition: effects of intra- and interspecific host characteristics
}

\author{
Juliann Eve Aukema and Carlos Martínez del Rio
}

Aukema, J. E. and Martínez del Rio, C. 2002. Variation in mistletoe seed deposition: effects of intra- and interspecific host characteristics. - Ecography 25: 139-144.

\begin{abstract}
We investigated differences in host infection by a desert mistletoe, Phoradendron californicum, and examined one of the processes that contributes to these differences: variation in seed deposition among host individuals and species. In the Sonoran Desert, P. californicum parasitizes the sympatric leguminous trees Olneya tesota, Cercidium microphyllum, Prosopis velutina, Acacia constricta, and Acacia greggii. We hypothesized that seed deposition depends on host height and crown architecture. At a site in Arizona, frequency of infection did not reflect host relative abundance. Olneya tesota was parasitized at a higher frequency than expected from its abundance and maintained the highest mistletoe loads per individual host. In contrast, $P$. velutina was infected less frequently than expected. Infection frequency increased with host tree height for all hosts. Mistletoe seed deposition by avian dispersers differed among host species and was disproportionately high in $O$. tesota and $P$. velutina. Seed deposition was higher in infected than in non-infected host trees, and increased with tree height in $O$. tesota but not in C. microphyllum. We suspect that increased seed deposition with height in $O$. tesota may be due to the preference of seed-dispersing birds for higher perches. Some host tree species, such as C. microphyllum and A. constricta, probably received fewer mistletoe seeds because birds avoid hosts with dense and spiny crowns. Mistletoe populations are plant metapopulations in which host trees are patches and the frequency of infection in each host species/patch type is the result of interspecific differences in the balance between mistletoe colonization and extinction. From this perspective, our study of host use and seed dispersal is a metapopulation study of patch occupancy and propagule distribution among available patch types. Our seed-dispersal study demonstrates that the mechanisms that create pattern in patchy plant populations can be investigated in mistletoe systems.
\end{abstract}

J.Aukema(jaukema@alumni.brown.edu), Dept of Ecology and Evolutionary Biology, Univ. of Arizona, Tucson, AZ 85721, USA (present address: Olympia Forestry Sciences Lab., 3625 93rd Ave. SW, Olympia, WA 98512-9193, USA). - C. Martínez del Rio, Dept of Zoology and Physiology, Univ. of Wyoming, Laramie, WY 82071-3166, USA.

Mistletoes are common aerial stem-parasites that infect vascular plants ranging from pines to cacti (Hawksworth 1983, Martínez del Rio et al. 1996). With a few notable exceptions, such as the explosively dispersed Arceuthobium spp., mistletoe seeds are dispersed by fruit-eating birds, many of which are highly specialized to consume their berries (Reid et al. 1995). After being deposited by a bird onto an appropriate host, a seed germinates and forms a haustorium that taps into the xylem of the host plant to absorb water, minerals and, in some cases, sugars and amino acids (Calder 1983, Marshall and Ehleringer 1990).

Mistletoes range from extremely host specific (e.g. Arceuthobium apachecum) to host generalist (e.g. Dendrophthoe falcata) (Reid et al. 1995, Norton and Carpenter 1998). Often, the prevalence and intensity of mistletoe infections differ among host species (Yan 1993). The differential use of hosts by mistletoes within a site has been explained by three processes. First, because birds may perch and defecate mistletoe seeds

Accepted 21 June 2001

Copyright (C) ECOGRAPHY 2002

ISSN 0906-7590

ECOGRAPHY 25:2 (2002) 
more frequently on some hosts than on others, seed rain may differ among hosts (Reid 1989). Second, mistletoe seedlings may become established more successfully on some host species than others (Reid et al. 1995). Third, adult mistletoes may differ in persistence among host species (Hoffmann et al. 1986).

Phoradendron californicum, the desert mistletoe, is found from southern Utah to northern Mexico (Kearney and Peebles 1960). In the Sonoran desert, it infects Prosopis spp. (mesquite), Cercidium spp. (palo verde), Olneya tesota (ironwood) and Acacia spp. (acacia). Here we describe patterns of host use by $P$. californicum in the Sonoran Desert at a site in which it infects several species of trees. We also describe variation, both between and among hosts, in one of the processes that can produce differences in host use: the seed rain generated by seed-dispersing birds. In addition to exploring interspecific differences in infection and seed rain, we also investigate some of the factors that can lead to intraspecific variation in infection and seed rain. Specifically, we investigated whether host tree height was correlated with the probability or intensity of parasitism and whether tree height or current parasite load affected the probability of a tree receiving mistletoe seeds. Because host trees continue growing throughout their lives, height can be used as a rough approximation of the relative age of trees. We expected taller, and therefore older, trees to have a higher incidence of parasitism (Overton 1994, Martínez del Rio et al. 1995, Lei 1999), both because they would have more time to accumulate mistletoes and because phainopeplas (Phainopepla nitens), the avian dispersers of P. californicum seeds, use conspicuous perching as a form of territorial display (Walsberg 1977). Because mistletoes represent a food resource to which phainopeplas can be expected to respond, we hypothesized that previously infected trees were more likely to receive seeds, and therefore would be more likely to become reinfected (Martínez del Rio et al. 1995).

Mistletoe populations can be envisioned as assemblages of plants inhabiting different patch types represented by host species. The frequency of infection in each patch type/host species is the result of differences in the balance between colonization and extinction (Overton 1994). Overton (1994) suggested that mistletoe populations can be studied using a metapopulation perspective (but see Hanski and Gilpin 1991). From this perspective, our study of host use and seed dispersal can be conceived as a study of propagule distribution, which is one of the determinants of colonization among available patches (Hansson 1991).

\section{Study sites and methods}

We conducted this study in the Silverbell Mountains west of Marana, Arizona, USA $\left(32^{\circ} 27^{\prime} \mathrm{N}, 111^{\circ} 27^{\prime} \mathrm{W}\right)$ in January and February 1998. The vegetation of this area is characterized as upland Sonoran Desert scrub (Turner and Brown 1994) with a relatively high diversity of mistletoe host trees. We used two data sets for this study. First, we determined the relative abundance of each host tree species at the site by following twentythree 50-m strip transects radiating from an arbitrarily selected central location. We used these data (dataset 1, Table 1) only for analyses that depended on relative abundance of host species. Each transect comprised a sample area of $400 \mathrm{~m}^{2}$; all individuals of each host species (Acacia constricta, Acacia greggii, Cercidium microphyllum, Olneya tesota, and Prosopis velutina) were counted within $4 \mathrm{~m}$ of each side of the transect line. For each individual, we recorded species, tree height, the number of mistletoe plants in the tree and the number of mistletoe seeds defecated onto each tree. Because the seeds are large and light-colored, in contrast to the bark of hosts, they are easy to count by visually inspecting branches. Once deposited on a tree, the sticky viscin surrounding the seed adheres it to the branch, making it difficult to dislodge. Seeds from previous years are easily distinguished by their bleached color and crumbly texture. To increase our sample size of the two most frequently parasitized hosts, we recorded the same variables for all trees in a straight line, from the same origin, until we reached 100 individuals of both $C$. microphyllum and $O$. tesota. We used the combined, larger data set (dataset 2) for the majority of analyses, especially for intraspecific analyses and interspecific analyses that did not depend on relative abundance.

Table 1. Relative abundance, number infected, and number of individuals receiving seeds among the hosts of $P$. californicum. Data are based on $23,50 \times 8 \mathrm{~m}$ transects that included 168 host trees (dataset 1). Values in parentheses are expected values, assuming that numbers of individuals that were parasitized and that received seeds were independent of species. The overall frequency of parasitism was $24.4 \%$ and the overall frequency of individuals that received seeds was $32.7 \%$.

\begin{tabular}{lccc}
\hline Species & Number of individuals & Parasitized & Receiving seeds \\
\hline Cercidium microphyllum & 93 & $21(22.7)$ & $21(30.4)$ \\
Acacia constricta & 37 & $5(9.0)$ & $6(12.1)$ \\
Olneya tesota & 21 & $15(5.1)$ & $16(6.8)$ \\
Prosopis velutina & 14 & $0(3.4)$ & $12(4.6)$ \\
Acacia greggii & 3 & $0(0.7)$ & $0(1)$ \\
Total & 168 & 41 & 55 \\
\hline
\end{tabular}




\section{Results}

\section{Interspecific patterns of infection}

Cercidium microphyllum (mean height $\pm \mathrm{SE}=3.3 \pm 0.2$ $\mathrm{m}, \mathrm{N}=101$ ) was the most abundant host, followed by A. constricta (mean height $\pm \mathrm{SE}=2.0 \pm 0.1 \mathrm{~m}, \mathrm{~N}=62$ ), $O$. tesota (mean height $\pm \mathrm{SE}=4.5 \pm 0.1, \mathrm{~N}=103$ ), and $P$. velutina (mean height $\pm \mathrm{SE}=3.6 \pm 0.2, \mathrm{~N}=24$ ). Acacia greggii was the least common host species (data set 1, Table 1). Frequency of infection differed significantly among species (one-way ANOVA, $\mathrm{F}_{4,168}=10.04$, $\mathrm{p}<0.001)$ and did not reflect relative host species abundance $\left(\chi_{4,168}^{2}=24.86, \mathrm{p}<0.001\right.$; Table 1$)$. Olneya tesota was infected at a much higher frequency than expected from its abundance: this species accounted for $36.6 \%$ of all parasitized trees but made up only $12.5 \%$ of all host trees sampled. At the other extreme, no $P$. velutina individuals were infected in the first set of transects but this species represented $8.3 \%$ of all trees surveyed (Table 1). We consider P. velutina and A. greggii hosts of $P$. californicum at our site because outside of our transects we encountered infected individuals and because at other sites these species are frequently infected.

The number of mistletoes per host individual differed significantly among species $\left(\mathrm{F}_{2,259}=14.5, \mathrm{p}<0.0001\right)$. Olneya tesota had the highest number of mistletoes per individual (mean parasite load $\pm \mathrm{SE}=2.8 \pm 0.5, \mathrm{~N}=$ 96). Cercidium microphyllum and $A$. constricta individuals had much lower parasite loads $(0.6 \pm 0.21, \mathrm{~N}=101$ and $0.3 \pm 0.14, \mathrm{~N}=62$, respectively). The difference in parasite loads among these three species was, in part, due to the higher mistletoe prevalence (proportion of trees infected) in O. tesota. However, when only parasitized individuals were analyzed, the same pattern emerged. There were significant species differences in parasite loads among infected individuals $\left(\mathrm{F}_{2,71}=5.1\right.$, $\mathrm{p}<0.0084)$ and infected $O$. tesota individuals had higher parasite loads $(6.5 \pm 0.9, \mathrm{~N}=41)$ than infected C. microphyllum $(2.8 \pm 0.8, \mathrm{~N}=23)$ and $A$. constricta $(2.9 \pm 0.9, \mathrm{~N}=7)$ individuals.

The frequency with which different species received seeds in our sample differed significantly among species (one-way ANOVA, $\mathrm{F}_{4,296}=24.8, \mathrm{p}<0.0001$ ) and the frequency of seed reception did not reflect relative host species abundance $\left(\chi_{4,168}^{2}=31.12, \mathrm{p}<0.001\right.$; Table 1$)$. Olneya tesota and $P$. velutina received seeds more frequently than expected from their relative abundances (Table 1) and C. microphyllum and both species of Acacia received seeds less frequently than expected.

\section{Intraspecific patterns}

The frequency of parasitized hosts increased significantly with tree height in $O$. tesota, C. microphyllum and $A$. constricta (logistic regression, $\mathrm{p}<0.001$, Fig. 1).

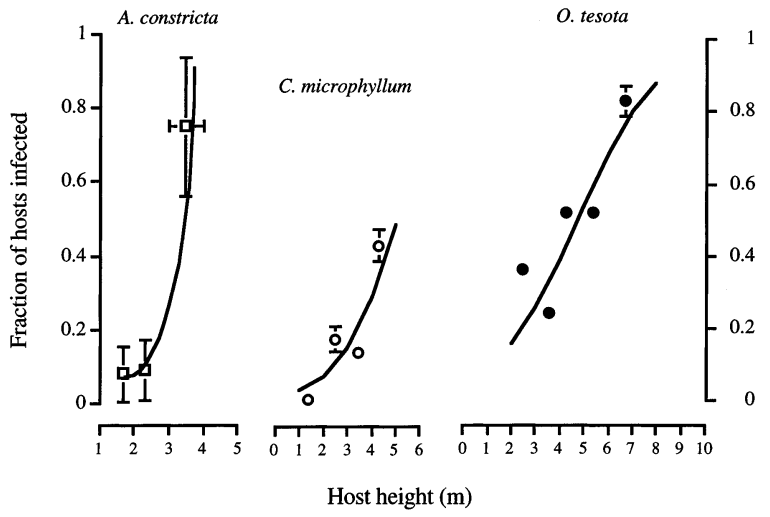

Fig. 1. The fraction of infected hosts increased with tree height in C. microphyllum, O. tesota and A. constricta. Curves were fitted using logistic regression $(O$. tesota: logit $(\mathrm{p})=-2.91+0.61$ (height) $, \quad \chi^{2}=12.5, \quad \mathrm{p}=0.0004, \quad \mathrm{~N}=102$, C. microphyllum: logit $(\mathrm{p})=-4.44+0.91$ (height), $\chi^{2}=10.1$, $\mathrm{p}=0.0015, \mathrm{~N}=101$ and $A$. constricta: $\operatorname{logit}(\mathrm{p})=-5.96+$ 1.82 (height), $\chi^{2}=8.4, p=0.0038, N=62$ ). Trees were divided into height classes for visual clarity in the figure: points are means and bars are SE.

The number of mistletoes per host increased significantly with height in O. tesota $\left(\mathrm{r}_{\mathrm{s}}=0.57, \mathrm{~N}=21, \mathrm{p}=\right.$ $0.0065)$ and $C$. microphyllum $\left(\mathrm{r}_{\mathrm{s}}=0.32, \quad \mathrm{~N}=91\right.$, $\mathrm{p}=0.0021)$.

Parasitized C. microphyllum trees were significantly more likely to receive seeds than were unparasitized trees (logistic regression, $\beta_{\text {infection, }} \chi^{2}=21.18, \mathrm{p}<$ $0.0001, \mathrm{~N}=101$ ). However, tree height had no effect on the frequency of seed deposition in this species (logistic regression, infected $\chi^{2}=0.96, \mathrm{p}=0.327, \mathrm{~N}=23$; uninfected $\chi^{2}=0.184, \mathrm{p}=0.668, \mathrm{~N}=78$; Fig. 2). In contrast, in $O$. tesota, presence of seeds increased with both height and infection (logistic regression, height $\chi^{2}=$ 9.47, $\mathrm{p}=0.0021$; infection $\chi^{2}=20.15, \mathrm{p}<0.0001, \mathrm{~N}=$ 102; Fig. 2).

In $A$. constricta, $C$. microphyllum, and $O$. tesota, the number of seeds deposited on a tree was significantly correlated with the number of mistletoes found on the tree $\left(A\right.$. constricta: $\mathrm{r}_{\mathrm{s}}=0.50, \mathrm{~N}=59, \mathrm{p}<0.0001 ; C$. microphyllum: $\mathrm{r}_{\mathrm{s}}=0.48, \mathrm{~N}=101, \mathrm{p}<0.0001 ;$ O. tesota: $\left.\mathrm{r}_{\mathrm{s}}=0.72, \mathrm{~N}=96, \mathrm{p}<0.0001\right)$. Tree height had no influence on the number of seeds received by $A$. constricta or C. microphyllum. However, in O. tesota, height was also positively correlated with number of seeds deposited $\left(\mathrm{r}_{\mathrm{s}}=0.42, \mathrm{~N}=102, \mathrm{p}<0.0001\right)$.

\section{Discussion}

Interspecific differences in mistletoe prevalence are likely the result of several non-exclusive processes. First, they may result from differential seed deposition resulting from the perching preferences of the mistletoe's avian dispersers. Second, we speculate that they 
may result from differential susceptibility of hosts to parasites or differential persistence of mistletoes on different host species. Our study emphasized the first of these processes, differential seed deposition. This discussion is organized in three sections. First, we identify the interacting factors that lead to inter- and intraspecific variation in seed rain. We submit that host height, previous infection, and host architecture are the main factors that shape seed deposition. The second section identifies seedling establishment as another factor that shapes infection prevalence. A third section frames our study in the broader context of structured plant populations. We claim that mistletoes are suitable systems to scrutinize the patterns created by seed-dispersal in plant metapopulations.

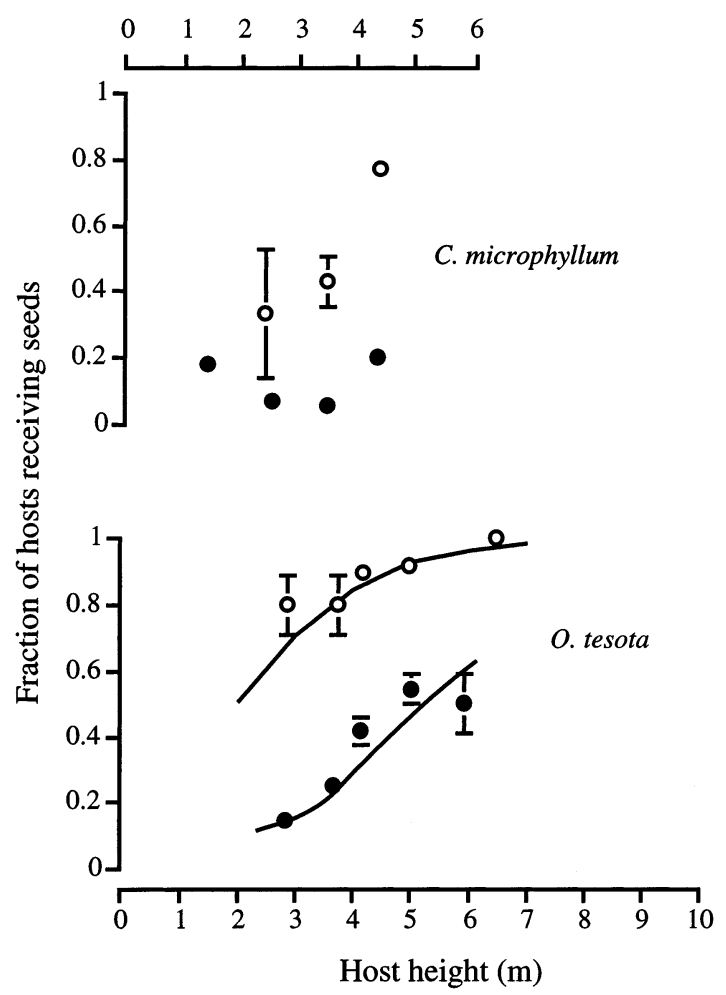

Fig. 2. The fraction of hosts receiving seeds increased with height in O. tesota (lower panel). Previously infected hosts (open circles) had a higher probability of receiving seeds than uninfected hosts (filled circles). Logistic regression: $\operatorname{logit}(\mathrm{p})=$ $-2.825+0.857$ (height) +1.414 (infection) (intercept $\chi^{2}=5.57$, $\mathrm{p}=0.018$; height $\chi^{2}=9.48, \mathrm{p}=0.002$; infect $\chi^{2}=20.15, \mathrm{p}<$ $0.0001 ; \mathrm{N}=102$ ). In contrast, in $C$. microphyllum (upper panel) there was no significant effect of host height (the logistic regression coefficients for height were non-significant for infected and non-infected trees $\chi^{2}<1, \mathrm{p}>0.1, \mathrm{~N}=101$ ). However there was a highly significant effect of previous infection on the fraction of hosts receiving seeds (logistic regression coefficient for infection status, $\chi^{2}=21.18, \mathrm{p}<$ $0.001, \mathrm{~N}=101$ ). Trees have been divided into size classes for visual clarity. Bars are SE. Curves were fitted using the logistic equation shown above.
Height, previous infection, tree architecture and seed deposition

Among the most frequently infected hosts, $61 \%$ of $O$. tesota hosts received seeds, whereas only $22 \%$ of $C$. microphyllum, and only $14 \%$ of $A$. constricta received seeds. The difference in seed reception among these species can probably be attributed to the preference of phainopeplas for O. tesota over C. microphyllum and $A$. constricta as perch trees. The possible preference of phainopeplas for O. tesota over C. microphyllum and $A$. constricta can be detected in both infected and non infected trees. Most (91\%) of the infected O. tesota individuals received seeds, whereas only $61 \%$ and $50 \%$ of the infected C. microphyllum and A. constricta trees received seeds. Furthermore, a large fraction $(35 \%)$ of uninfected $O$. tesota trees received seeds, whereas relatively few uninfected $C$. microphyllum $(10 \%)$ and $A$. constricta $(9 \%)$ trees received seeds.

Phainopeplas may perch preferentially, and hence deposit seeds disproportionately, on $O$. tesota because it is, on average, the tallest host tree. It is also the host with the highest parasite loads, and hence the highest mistletoe fruit availability. In $O$. tesota, both infected and uninfected trees were more likely to receive seeds if they were taller. However, height was not the only factor determining seed rain. Although C. microphyllum and $P$. velutina were very similar in height, a higher fraction of $P$. velutina trees $(83 \%)$ received seeds. Recall that the frequency of parasitism in $P$. velutina is very low (Table 1). Hence the high seed rain in this species cannot be attributed to a response of birds to high parasite infection.

Following Overton (1993), we hypothesize that, in addition to height, the architecture of trees may influence their attractiveness as perches. Prosopis velutina and $O$. tesota tend to have open canopies that allow easy perching, whereas $C$. microphyllum individuals tend to have a dense canopy that bristles with flexible thorn-like branchlets. Acacia constricta individuals have dense canopies and branches armed with sharp grabbing thorns. Larson (1991) found that birds spent relatively more time perching in $P$. velutina individuals than in C. microphyllum, and Acacia spp. Overton (1993) found that, in communities with varying proportions of host species, phainopeplas preferred Prosopis and avoided Cercidium as perches. This ranking in the perching preference of birds is similar to our observations of seed deposition.

Within a host species, previously infected trees were significantly more likely to receive seeds than uninfected trees. Furthermore, the number of seeds that a tree received correlated positively with the number of mistletoes infecting it. As observed by Larson (1991, 1996), phainopeplas spend more time in trees with many mistletoes, and may use mistletoes as a cue for visiting a tree and for perching on it. The preference of mistletoe seed dispersers for already parasitized trees 
seems to be a general pattern in mistletoe-host-disperser systems (see Martínez del Rio et al. 1995). This process has been labeled "conspecific attraction" by Stamps (1988) and can lead to two important consequences: 1) it may facilitate the reinfection of already parasitized trees and thus lead to strong aggregation of mistletoes in hosts (Stamps 1988, Aukema and Martínez del Rio 2002) and 2) it may lower the fraction of occupied hosts/patches accessible to the mistletoe metapopulation (Ray et al. 1991).

\section{Variation in establishment}

Elucidating differential seed deposition is a necessary step in the search for the causes of variation in mistletoe infection among host individuals and species. Because the presence and intensity of a mistletoe infection depends also on establishment and persistence, this step alone is not sufficient. Due to physiological or morphological differences between hosts, establishment and persistence of mistletoes may differ among species (Hoffmann et al. 1986, Yan 1993). Prosopis velutina exemplifies the significance of establishment as a determinant of prevalence. This species had the highest rate of seed reception, with $83.3 \%$ of individuals receiving seeds. Curiously, $P$. velutina showed very low infection prevalence, a characteristic that cannot be explained by low seed deposition and hence may be attributed to low establishment success. In contrast, at a site in another nearby mountain range (the Santa Rita Mountains) $P$. velutina is heavily parasitized by $P$. californicum, with rates of infection as high as 75\% (Stamps 1988, Aukema 2001). Although Cercidium spp. and Acacia spp. are present at the Santa Rita site, P. velutina is the numerically dominant host and the most frequently infected one. Previous studies have provided preliminary evidence for the existence of geographically isolated host races in the genus Phoradendron (Clay et al. 1985, Glazner et al. 1988, Overton 1997). We hypothesize that $P$. californicum in the Silverbell mountains of Arizona has reduced ability to infect $P$. velutina.

\section{Conclusion: mistletoes and plant metapopulations}

The population of $P$. californicum at the Silverbell Mountains can be viewed as an assemblage of mistletoe groups inhabiting discrete patch types represented by host species. The frequency of infection in each host results from interspecific differences in the balance between mistletoe colonization and extinction (Overton 1994). The process of colonization of a patch depends on seed deposition and establishment. Hence, differences in seed rain among host species should be important determinants of interspecific differences in infection. Indeed, excluding $P$. velutina, which seems to be relatively unaffected by mistletoe infection at our site, the most frequently infected species (O. tesota) was also the one that received the highest number of seeds.

Although it is tempting to attribute the interspecific differences in mistletoe prevalence reported here to variation in seed rain, other factors may also play an important role. Olneya tesota is a slow-growing and extraordinarily long-lived species (Nabhan and Carr 1994). Individuals that are several hundred years old are not uncommon at our site (Suzán 1994). In contrast, $C$. microphyllum and $A$. constricta grow relatively quickly, and probably have higher population turnover (Turner 1963). Thus, O. tesota individuals have had a longer time period to accumulate mistletoes than $C$. microphyllum and $A$. constricta individuals of equal height. In addition to differences in growth rate and age, it is likely that mistletoes have contrasting success at establishing among different hosts (Thomson and Mahall 1983), and that established mistletoes have dissimilar mortalities among host species (Aukema unpubl.). Olneya tesota, C. microphyllum and A. constricta differ in morphological and physiological characteristics that are likely to influence the growth and survival of the mistletoes that infect them (Yan 1993 and references therein). Understanding interspecific differences in mistletoe infection requires thorough comprehension of the biological differences in the interaction between several hosts and their parasite.

Although our study touched upon only a single factor that impinges on parasitism frequency, it highlighted a significant aspect of the interaction between mistletoes, hosts, and avian-seed dispersers. As Overton (1994) suggested, mistletoe populations may be profitably viewed as structured metapopulations. We have demonstrated that the factors that govern differential seed rain, and hence patch colonization, can be recognized and that their relative importance can be disentangled. Other determinants of patch occupancy, such as success in seedling establishment, patch longevity, and the comparative demography of mistletoes within hosts can be studied with a combination of experimental approaches and long-term observations. Husband and Barrett (1996) lamented the paucity of metapopulation studies in plants and identified the difficulties that plant populations can pose for metapopulation perspectives. The biology of mistletoes permits overcoming many of these difficulties. Mistletoes show much promise as model systems to investigate the mechanisms and processes that create pattern in spatially structured plant populations.

Acknowledgements - We would like to thank John King for help in the field and Judie Bronstein for lending us a measuring pole; Blair Wolf, Rachel Levin, Asher Cutter, Greg Hayward, Nancy Stanton, David McDonald, and Yaron Ziv for comments on the manuscript. This work was funded by a NSF Graduate Research Fellowship and a Tinker Graduate Research Grant (Latin American Area Center, Univ. of Arizona). This paper is dedicated to those who had the foresight to 
suggest the creation of the Ironwood National Monument at the site where our study was conducted.

\section{References}

Aukema, J. E. 2001. Dispersal and spatial distribution of the desert mistletoe, Phoradendron californicum, at multiple scales: patterns, processes and mechanisms. - Ph.D. thesis, Univ. of Arizona, Tucson, AZ.

Aukema, J. E. and Martínez del Rio, C. 2002. Mistletoes as parasites and seed-dispersing birds as disease vectors: current understanding, challenges and opportunities. - In: Levey, D. J., Silva, W. R. and Galletti, M. (eds), Seed dispersal and frugivory: ecology, evolution and conservation. CAB International, pp. 99-110.

Calder, D. M. 1983. Mistletoes in focus: an introduction. - In: Calder, M. and Bernhardt, P. (eds), The biology of mistletoes. Academic Press, pp. 1-18.

Clay, K., Demet, D. and Rejmanek, M. 1985. Experimental evidence for host races in mistletoe Phoradendron tomentosum (Viscaceae). - Am. J. Bot. 72: 1225-1231.

Glazner, J. T., Devlin, B. and Ellstrand, N. 1988. Biochemical and morphological evidence for host race evolution in desert mistletoe, Phoradendron californicum (Viscaceae). Plant Syst. Evol. 161: 13-21.

Hanski, I. and Gilpin, M. 1991. Metapopulation dynamics: concepts, models, and observations. - In: Gilpin, M. and Hanski, I. (eds), Metapopulation dynamics: empirical and theoretical investigations. Academic Press, pp. 3-16.

Hansson, L. 1991. Dispersal and connectivity in metapopulations. - In: Gilpin, M. and Hanski, I. (eds), Metapopulation dynamics: empirical and theoretical investigations. Academic Press, pp. 89-103.

Hawksworth, F. G. 1983. Mistletoes as forest parasites. - In: Calder, M. and Bernhardt, P. (eds), The biology of mistletoes. Academic Press, pp. 317-333.

Hoffmann, A. J. et al. 1986. Tristerix tetrandus (Loranthaceae) and its host plants in the chilean matorral: patterns and mechanisms. - Oecologia 6: 202-206.

Husband, B. C. and Barrett, S. C. H. 1996. A metapopulation perspective in plant population biology. - J. Ecol. 84: 461-469.

Kearney, T. H. and Peebles, R. H. 1960. Arizona flora. Univ. of Arizona Press, CA.

Larson, D. 1991. Ecology of desert mistletoe seed dispersal. Unpubl. Ph.D. thesis, Univ. of Illinois, Chicago, IL.

Larson, D. 1996. Seed dispersal by specialist versus generalist foragers: the plant's perspective. - Oikos 76: 113-120.

Lei, S. 1999. Age, size and water status of Acacia greggii influencing the infection and reproductive success of Phoradendron californicum. - Am. Midl. Nat. 141: 358365.
Marshall, J. D. and Ehleringer, J. R. 1990. Are xylem-tapping mistletoes partially heterotrophic? - Oecologia 84: 244248.

Martínez del Rio, C. et al. 1995. The influence of cactus size and previous infection on bird deposition of mistletoe seeds. - Aust. J. Ecol. 20: 571-576.

Martínez del Rio, C. et al. 1996. Seed dispersers as disease vectors: bird transmission of mistletoe seeds to host plants. - Ecology 77: 912-921.

Nabhan, G. P. and Carr, J. L. 1994. Ironwood: an ecological and cultural keystone of the Sonoran Desert. - Occas. Pap. Conserv. Biol. 1: 9-27.

Norton, D. A. and Carpenter, M. A. 1998. Mistletoes as parasites: host specificity and speciation. - Trends Ecol. Evol. 13: $101-105$.

Overton, J. M. 1993. Dispersal in mistletoes and models. Unpubl. Ph.D. thesis, Univ. of California, Los Angeles, CA.

Overton, J. M. 1994. Dispersal and infection in mistletoe metapopulations. - J. Ecol. 82: 711-723.

Overton, J. M. 1997. Host specialization and partial reproductive isolation in desert mistletoe (Phoradendron californicum). - Southwest. Nat. 42: 201-209.

Ray, C., Gilpin, M. and Smith, A. T. 1991. The effect of conspecific attraction on metapopulation dynamics. - In: Gilpin, M. and Hanski, I. (eds), Metapopulation dynamics: empirical and theoretical investigations. Academic Press, pp. $123-134$.

Reid, N. 1989. Dispersal of mistletoes by honeyeaters and flowerpeckers: components of seed dispersal quality. Ecology 70: 137-145.

Reid, N., Smith, N. M. and Yan, Z. 1995. Ecology and population biology of mistletoes. - In: Lowman, M. D. and Nadkarni, N. M. (eds), Forest canopies. Academic Press, pp. 285-310.

Stamps, J. A. 1988. Conspecific attraction and aggregation in territorial species. - Am. Nat. 131: 329-347.

Suzán, H. 1994. Ecological effects of exploitation of Olneya tesota Gray and associated species in the Sonoran Desert. - Unpubl. Ph.D. thesis, Arizona State Univ., Tempe, AZ

Thomson, V. E. and Mahall, E. 1983. Host specificity by a mistletoe, Phoradendron villosum (Nutt.) Nutt. subsp. villosum, on three oak species in California. - Bot. Gaz. 144: 124-131.

Turner, R. M. 1963. Growth in four species of Sonoran Desert trees. - Ecology 44: 760-765.

Turner, R. M. and Brown, D. E. 1994. Sonoran Desertscrub. - In: Brown, D. E. (ed.), Biotic communities: southwestern United States and northwestern Mexico. Univ. of Utah Press, Salt Lake City, pp. 181-222.

Walsberg, G. E. 1977. Ecology and energetics of contrasting social systems in Phainopepla nitens (Aves: Ptilogonatidae). - Univ. of California Publ. in Zool. 108: 1-63.

Yan, Z. 1993. Resistance to haustorial development of two mistletoes, Amyema preissi (Miq.) and Lysiana exocarpi (Behr) Tieghem spp. exocarpi (Loranthaceae) on host and non-host species. - Int. J. Plant Sci. 154: 386-394. 